\section{Treatment of canine atopic dermatitis with azathioprine: a pilot study}

\section{FAVROT, P. ReICHMUth, T. OLIVRY}

AZATHIOPRINE (AZA) is an antimetabolite chemotherapy drug that has been used recently for the successful treatment of human beings, both adults and children, with atopic dermatitis, a non-contagious but itchy inflammation of the skin (Meggitt and Reynolds 2001, Berth-Jones and others 2002, Meagher and others 2002, Murphy and Atherton 2003, Malthieu and others 2005). This short communication describes an open, uncontrolled trial designed to test whether AZA monotherapy is safe and effective for the short-term treatment of canine atopic dermatitis.

Twelve dogs (eight male, four female) of 12 different breeds, aged between one and eight years old (mean threeand-a-half years), were included in the trial. All of the dogs were diagnosed with non-seasonal atopic dermatitis according to standard methods (DeBoer and Hillier 2001). Oral glucocorticoids and cyclosporine were withdrawn from treatment for at least four weeks and long-lasting injectable glucocorticoids for eight weeks before the trial. All of the dogs were treated solely with 2 to $2.5 \mathrm{mg} / \mathrm{kg}$ (mean $2 \cdot 2$ $\mathrm{mg} / \mathrm{kg}$ ) AZA (Imurek; Glaxosmithkline), once daily for eight weeks. Skin lesions were graded at weeks 0, 2, 4 and 8 using the third version of the Canine Atopic Dermatitis Extent and Severity Index (CADESI) (Olivry and others 2007), the version recently validated by the International Task Force on Canine Atopic Dermatitis. At each visit, owners were asked to estimate the level of pruritus by drawing a mark on a $10 \mathrm{~cm}$ visual analogue scale. At the end of the treatment (or earlier for dogs withdrawn from the study) investigators and owners together evaluated the efficacy of AZA therapy as 'none', 'poor', 'fair', 'good' or 'excellent'. At each visit, owners were asked to report any side effects of the drug. Complete blood counts and the activity of serum alkaline phosphatase (AP) and alanine aminotransferase (ALAT) were monitored after two, four and eight weeks.

Seven dogs completed the study. Two subjects were withdrawn at the owners' request because of lack of improvement in signs of atopic dermatitis (dogs 2 and 4), and AZA was discontinued in three further dogs because of unacceptable side effects (dogs 3, 7 and 12). In two dogs (dogs 1 and 5), both CADESI and pruritus scores substantially decreased during the eight weeks of AZA administration (Table 1). In both dogs, the efficacy was rated as 'excellent'. In five $\operatorname{dogs}(\operatorname{dogs} 6$ and 8 to 11), CADESI and/or pruritus scores declined from baseline by less than 50 per cent, and the efficacy of the treatment was rated as 'fair'. Finally, in one $\operatorname{dog}(\operatorname{dog} 7)$, scores decreased within two weeks of AZA administration, but side effects developed and AZA was discontinued (efficacy was rated as 'good').

In six dogs, low-level elevations of liver enzyme activity were uncovered at the start of the study (Table 2). This is likely to reflect previous glucocorticoid administration. Following AZA intake, the activity of AP or ALAT rose above normal in 10 of the 12 dogs ( 83 per cent). Clinical signs suggestive of liver disease motivated the withdrawal of three dogs, all with high AP and ALAT activity. All dogs recovered uneventfully without any treatment other than discontinuation of AZA administration. In the other seven dogs with elevated liver enzyme activity, there were no signs suggestive of liver damage. Mild lymphopenia was observed in three dogs, but anaemia and neutropenia were not uncovered in any of the dogs.

\begin{tabular}{|c|c|c|c|c|c|c|c|c|c|}
\hline \multirow{2}{*}{ Dog } & \multirow{2}{*}{$\begin{array}{c}\text { Dose } \\
(\mathrm{mg} / \mathrm{kg})\end{array}$} & \multirow{2}{*}{ Score } & \multicolumn{4}{|c|}{ Week } & \multicolumn{2}{|c|}{ Change of score* } & \multirow{2}{*}{$\begin{array}{c}\text { Overall } \\
\text { assessment }\end{array}$} \\
\hline & & & 0 & 2 & 4 & 8 & Points & $\%$ & \\
\hline 1 & $2 \cdot 0$ & $\begin{array}{l}\text { CADESI } \\
\text { Pruritus }\end{array}$ & $\begin{array}{r}52 \\
5\end{array}$ & $\begin{array}{r}25 \\
3\end{array}$ & $\begin{array}{r}20 \\
2\end{array}$ & $\begin{array}{r}16 \\
2\end{array}$ & $\begin{array}{r}-36 \\
-3\end{array}$ & $\begin{array}{l}-69 \\
-60\end{array}$ & Excellent \\
\hline \multirow[t]{2}{*}{2} & $2 \cdot 1$ & CADESI & 67 & 62 & $8 \overline{3}$ & WD & NA & NA & None \\
\hline & & Pruritus & 7 & 8 & 8 & WD & NA & NA & \\
\hline 3 & $2 \cdot 3$ & $\begin{array}{l}\text { CADESI } \\
\text { Pruritus }\end{array}$ & $\begin{array}{r}145 \\
7\end{array}$ & $\begin{array}{r}146 \\
8\end{array}$ & WD & WD & NA & NA & None \\
\hline \multirow[t]{2}{*}{4} & $2 \cdot 5$ & $\begin{array}{l}\text { Pruritus } \\
\text { CADESI }\end{array}$ & $\begin{array}{r}7 \\
85\end{array}$ & $\begin{array}{r}8 \\
160\end{array}$ & $\begin{array}{l}\text { WD } \\
\text { WD }\end{array}$ & $\begin{array}{l}\text { WD } \\
\text { WD }\end{array}$ & $\begin{array}{l}\text { NA } \\
\text { NA }\end{array}$ & $\begin{array}{l}\text { NA } \\
\text { NA }\end{array}$ & None \\
\hline & & Pruritus & 3 & 9 & WD & WD & NA & NA & \\
\hline \multirow[t]{2}{*}{5} & $2 \cdot 4$ & CADESI & 75 & 56 & 32 & 15 & -60 & -80 & Excellent \\
\hline & & Pruritus & 6 & 4 & 3 & 1 & -5 & -83 & \\
\hline \multirow[t]{2}{*}{6} & $2 \cdot 5$ & CADESI & 38 & 33 & 38 & 24 & -14 & -37 & Fair \\
\hline & & Pruritus & 4 & 3 & 5 & 2 & -2 & -50 & \\
\hline \multirow[t]{2}{*}{7} & $2 \cdot 3$ & CADESI & 53 & 25 & WD & WD & $\mathrm{NA}$ & NA & Good \\
\hline & & Pruritus & 6 & 2 & WD & WD & NA & NA & \\
\hline \multirow[t]{2}{*}{8} & $2 \cdot 1$ & CADESI & 58 & 75 & 50 & 45 & -13 & -22 & Fair \\
\hline & & Pruritus & 4 & 8 & 4 & 4 & 0 & 0 & \\
\hline \multirow[t]{2}{*}{9} & $2 \cdot 1$ & CADESI & 43 & 45 & 35 & 31 & -12 & -28 & Fair \\
\hline & & Pruritus & 5 & 5 & 5 & 5 & 0 & 0 & \\
\hline \multirow[t]{2}{*}{10} & $2 \cdot 1$ & CADESI & 67 & 54 & 32 & 45 & -22 & -33 & Fair \\
\hline & & Pruritus & 6 & 5 & 2 & 4 & -2 & -33 & \\
\hline \multirow[t]{2}{*}{11} & $2 \cdot 3$ & CADESI & 54 & 35 & 33 & 30 & -24 & -44 & Fair \\
\hline & & Pruritus & 7 & 5 & 5 & 4 & -3 & -43 & \\
\hline \multirow[t]{2}{*}{12} & $2 \cdot 1$ & CADESI & 89 & 112 & WD & WD & NA & NA & None \\
\hline & & Pruritus & 8 & 10 & WD & WD & NA & NA & \\
\hline
\end{tabular}

* From baseline

WD Withdrawn, NA Not applicable

In the present study, the administration of AZA, at a dosage of 2 to $2.5 \mathrm{mg} / \mathrm{kg}$ once daily for up to eight weeks, appeared to be effective and safe for the treatment of canine atopic dermatitis in only two of 12 dogs ( 17 per cent). In five of the dogs the improvements in signs was fair (less than 50 per cent reduction in scores). However, a reduction in clinical scores was noted at the first re-evaluation visit after two weeks in six dogs, suggesting that the pharmacodynamic action of AZA in dogs may be seen earlier than previously perceived (Plumb 2002). Overall, the efficacy of AZA monotherapy appears to be markedly lower than that of the two drugs with proven efficacy for the treatment of this disease (Olivry and Mueller 2003). Treatment of canine atopic dermatitis with oral glucocorticoids or cyclosporine for four to six weeks results in a halving of lesional scores in more than 50 per cent of the dogs treated (Olivry and Mueller 2003). Importantly, this pilot study, in which AZA was used without the concurrent administration of glucocorticoids, resulted in elevations of AP and/or ALAT in nearly all of the dogs treated (10 of 12). In three (30 per cent) of these dogs, there were concurrent clinical signs suggestive of liver damage.

AZA monotherapy, at the dosage used in the present study, has insufficient efficacy and too high a risk to recommend its general use for the treatment of atopic dermatitis in dogs.

\section{References}

BERTH-JONES, J., TAKWALE, A., TAN, E., BARCLAY, G., AGARWAL, S., AHMED, I., HOTCHKISS, K. \& GRAHAM-BROWN, R. A. (2002) Azathioprine in severe adult atopic dermatitis: a double-blind, placebocontrolled, crossover trial. British Journal of Dermatology 147, 324-330

DEBOER, D. J. \& HILLIER, A. (2001) The ACVD task force on canine atopic dermatitis (XV): fundamental concepts in clinical diagnosis. Veterinary Immunology and Immunopathology 81, 271-276

MALTHIEU, F., GUILLET, G. \& LARREGUE, M. (2005) Azatropin in severe atopic dermatitis: 24 cases. Annales de Dermatologie et de Venereologie 132, 168-170. In French

MEAGHER, L. J, WINES, N. Y. \& COOPER, A. J. (2002) Atopic dermatitis: review of immunopathogenesis and advances in immunosuppressive therapy. Australasian Journal of Dermatology 43, 247-254

MEGGITT, S. J. \& REYNOLDS, N. J. (2001) Azathioprine for atopic dermatitis.
Veterinary Record (2007) $160,520-521$

\section{Favrot, DVM, MSc,} DipECVD,

P. Reichmuth, DVM, PhD, DipACVD, DipECVD,

Clinic for Small Animal Internal Medicine, Dermatology Unit, Vetsuisse Faculty, University of Zurich, 8057 Zurich, Switzerland T. Olivry, MedVet, Department of Clinical Sciences, College of Veterinary Medicine, North Carolina State University, Raleigh, NC 27606, USA 
TABLE 2: Side effects of azathioprine therapy in 12 dogs with atopic dermatitis, after eight weeks of treatment

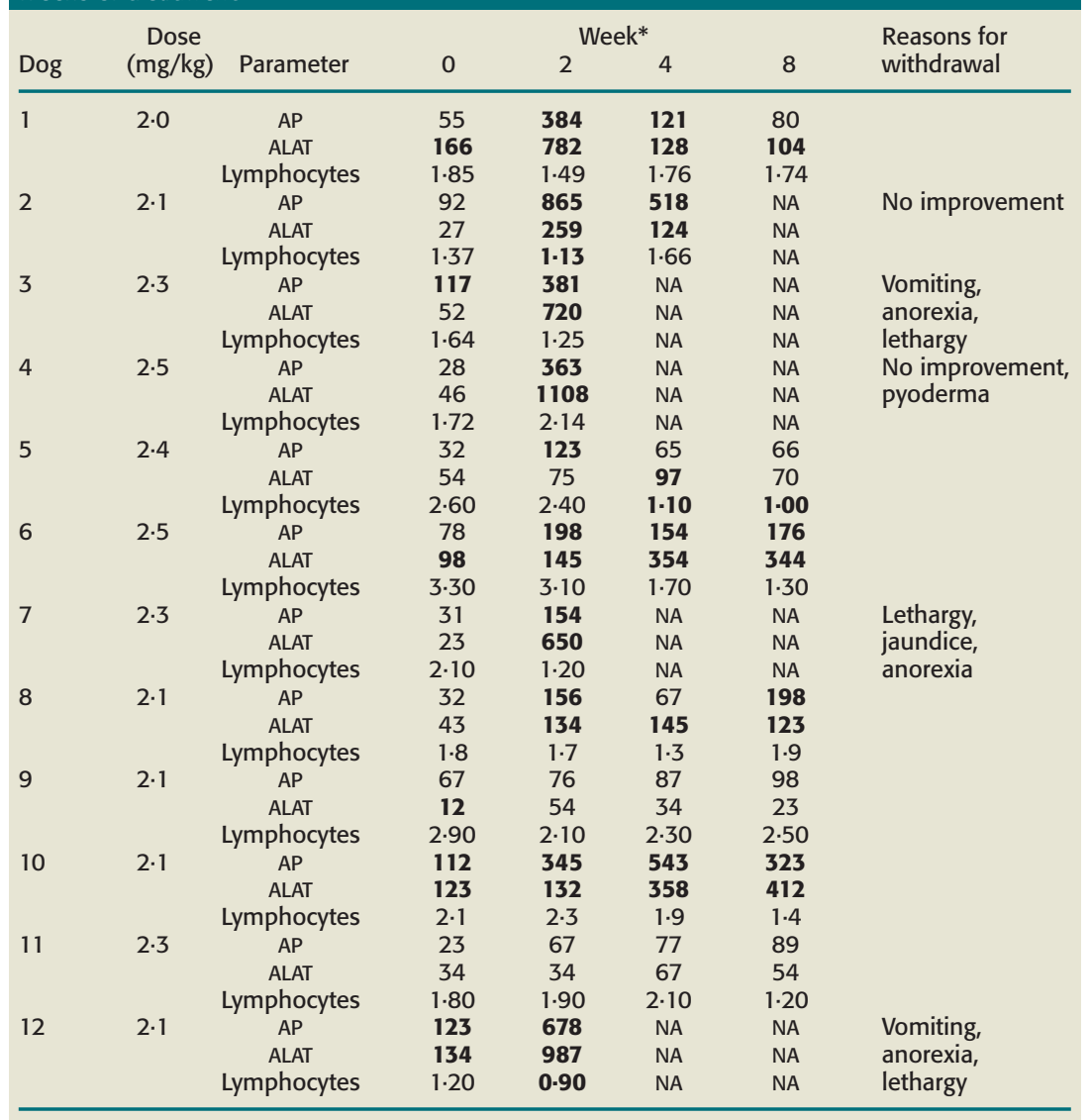

* Bold values are outside the normal range

AP Alkaline phosphatase (normal range 20 to $98 \mathrm{U} / \mathrm{I}$ ), ALAT Alanine aminotransferase (normal range 20 to $93 \mathrm{U} / \mathrm{I}$ ), Lymphocytes (normal range 1.15 to $3.4 \times 10^{3}$ cells/ $/ \mathrm{l}$ ), NA Not applicable
Clinical and Experimental Dermatology 26, 369-375

MURPHY, L. A. \& ATHERTON, D. J. (2003) Azathioprine as a treatment for severe atopic eczema in children with a partial thiopurine methyl transferase (TPMT) deficiency. Pediatric Dermatology 20, 531-534

OLIVRY, T., MARSELLA, R., IWASAKI, T., MUELLER, R. \& THE INTERNATIONAL TASK FORCE ON CANINE ATOPIC DERMATITIS (2007) Validation of CADESI-03, a severity scale for clinical trials enrolling dogs with atopic dermatitis. Veterinary Dermatology 18, 78-86

OLIVRY, T. \& MUELLER, R. S. (2003) Evidence-based veterinary dermatology: a systemic review of the pharmacotherapy of canine atopic dermatitis. Veterinary Dermatology 14, 121-146

PLUMB, D. C. (2002) Azathioprine. In Veterinary Drug Handbook. Ed D. C.

Plumb. Ames, Iowa University State Press. pp 86-88 